\title{
A Model to Determine Staff Levels, Cost, and Productivity of Hospital Units
}

\author{
Walton M. Hancock, Stephen M. Pollock, and Myeng-Ki Kim
}

\begin{abstract}
A methodology is presented with examples of the productivity, the staffing required, the resultant productivity, and costs that can be obtained for hospital units that are subject to random work demands such as laboratory, radiology, physical therapy, and nuclear medicine. The methodology assumes that the hospital has a labor productivity system that produces the RVUs or earned hours of work accomplished daily by shift. Factors considered are the distribution of the capabilities of the work force, the fatigue and delay allowances of the work standards, the quality of the work standards, the maximum amount of overtime that people will be asked to work, staffing policies such as constant or different staffing levels for each day of the week, and worker selection processes. Predicted results are compared with present practice, which indicates that substantial cost reductions can occur with the use of the methodology.
\end{abstract}

\section{INTRODUCTION}

Approximately $60 \%$ of current total hospital costs are due to labor. With the implementation of DRG forms of payment, the proper determination of how a hospital's departments should be staffed becomes of crucial importance.

Hospital labor has unique demands placed upon it because of varying work loads, variations in patient occupancy, the particular needs of individual patients, and the work load's changing on a day-to-day basis. Opportunities for leveling the work load are limited because most of the work must be done the same day (usually on the same shift) in order to properly treat the patient. In addition, typical lengths of stay in hospitals are 6 to 10 days, so that work load leveling (finishing the work tomorrow when it should have been done today) can also result in excess per diem costs due to increased lengths of stay. Another source of variation is in the capabilities of the members of the work force. Workers differ in their ability to absorb variations in work load demand relative to work standards. ${ }^{1-3}$

Discussions with hospital personnel and studies of principal units (including nursing, laboratory, radiology, and physical therapy) indicate that in the hospital environ-

From the Industrial and Operations Engineering Department, University of Michigan. 
ment, workers not only work at varying rates, they also tend to work to the limits of their capabilities when conditions warrant. The reasons include the following:

1. A high work load is often perceived by the work force early in the day. Thus, there is motivation to "work as hard as one can to get the work done."

2. The work force and management attitude is that one should work as hard as one can when the work load is high in order to provide the requested service.

3. Most of the work is labor-intensive, uncontrolled by a machine or the immediate input of another worker. Thus, workers can usually work at their capability if the situation requires it.

4. Work content varies widely. Workers move about, so that the same workers are not in immediate proximity to each other most of the time. Thus, the concept of equity of work rate (so many pieces per hour) does not dominate the environment.

5. Productivity measurements are conventionally made on a group (usually departmental) basis and are rarely feasible, or performed, on an individual basis. (This situation also reduces the formation of the concept of equity of work rates.)

\section{THE PRESENT SITUATION IN MANY HOSPITALS}

Since 1960, an increasing number of hospitals have been introducing and using labor productivity systems to assist in staffing decisions. Productivity, $P$, (in units of percent) is usually defined to be

$$
\begin{aligned}
P & =\frac{E H}{S T} \times 100 \\
\text { where } E H & =\text { earned hours, } \\
S T & =\text { worked staff hours }
\end{aligned}
$$

for a prespecified period of time over which productivity is measured (usually a week or a pay period).

The basis for determining $E H$ is usually a set of labor standards that have been established by the hospital's management engineering department, consultants, or professional organizations. The quality of these standards varies from poor (guesses) to excellent (time study or predetermined time based), ${ }^{4}$ with most somewhere in between. For purposes of this presentation, we will assume that the standards are "excellent" and represent the $100 \%$ level or "low task" level for a "normal" worker, which is the primary basis for labor standards in industrial organizations. ${ }^{3,5}$

Even if a hospital has a labor productivity system, important questions remain concerning the productivity that should be expected, how one should staff to achieve it, and the resultant costs. At present, productivity is usually between 85 and $90 \%$. This range is justified by such arguments as these: (a) "It's better than what existed when the labor information system was introduced" (frequently $60 \%$ to $65 \%$ ). (b) "No one is perfect; therefore, productivity has to be below $100 \%$." (c) "We negotiated the productivity."

As for the staffing decisions needed to attain these productivities, typical management responses are the following: (a) "We tell the supervisor that it is his/her problem to figure out how to staff and meet the productivity requirements." (b) "We average the $E H$ on a daily basis and staff accordingly." (c) "We staff according to the budget." 
In turn, the budgets needed to achieve this staffing (and resulting productivity), are determined by rules such as these: (a) "Budgets are set by the budget officer who is not involved in productivity considerations." (b) "We use position control budgeting, which is independent of changes in work load." (c) "We budget using the expected productivity."

These responses have a common theme: There is rarely a technical basis for determining what productivity levels could be achieved, how one should staff, and the resulting budget. Yet a technical basis is important because when the true potential productivity is known, the costs of compromises to gain acceptance by the work force and management will be available. In addition, the technology provides a basis for determining the losses or gains due to management policies regarding overtime, full- and part-time staff, the quality of worker selection, and other staffing philosophies.

\section{THE METHODOLOGY}

We now present a simple yet useful methodology to relate staffing decisions to productivity and budget, in the face of variability in both work force and work load.

\section{Demand}

For purposes of illustration, consider the daily shift demand (in $E H$ ) for a department, shown in Table 1.

Thus, for example, on Monday of Week 1, Shift 1, the number of earned hours credited to the department is 400 . This figure results from summing the (predetermined) labor standards for all of the work actually done on this shift day. It can usually be obtained from the accounts receivable files of the hospital computer system.

Examination of Table 1 reveals a variation (in $E H$ ) between days of the week and within the same day for different weeks. (These data are typical of laboratories, radiology, pharmacy, physical therapy, respiratory therapy, dietary, and nursing.) One way of expressing this variation is by a plot of the frequency distribution, as shown in Figure 1.

\section{Capability}

A worker's capability is defined to be the amount of work, relative to standards upon which earned hours are determined, that can be performed in any given period

Table 1. Demand in Earned Hours $(E H) / D a y$

\begin{tabular}{crrrrrr}
\hline Week no. & Monday & Tuesday & Wednesday & Thursday & Friday & Total \\
\hline 1 & 400 & 350 & 300 & 350 & 300 & 1,700 \\
2 & 600 & 450 & 275 & 400 & 275 & 2,000 \\
3 & 500 & 475 & 400 & 275 & 375 & 1,975 \\
4 & 450 & 375 & 350 & 350 & 425 & 1,950 \\
Total & 1,950 & 1,650 & 1,325 & 1,375 & 1,325 & 7,625 \\
Average & 488 & 413 & 331 & 344 & 331 & $(381.3)$ \\
\hline
\end{tabular}




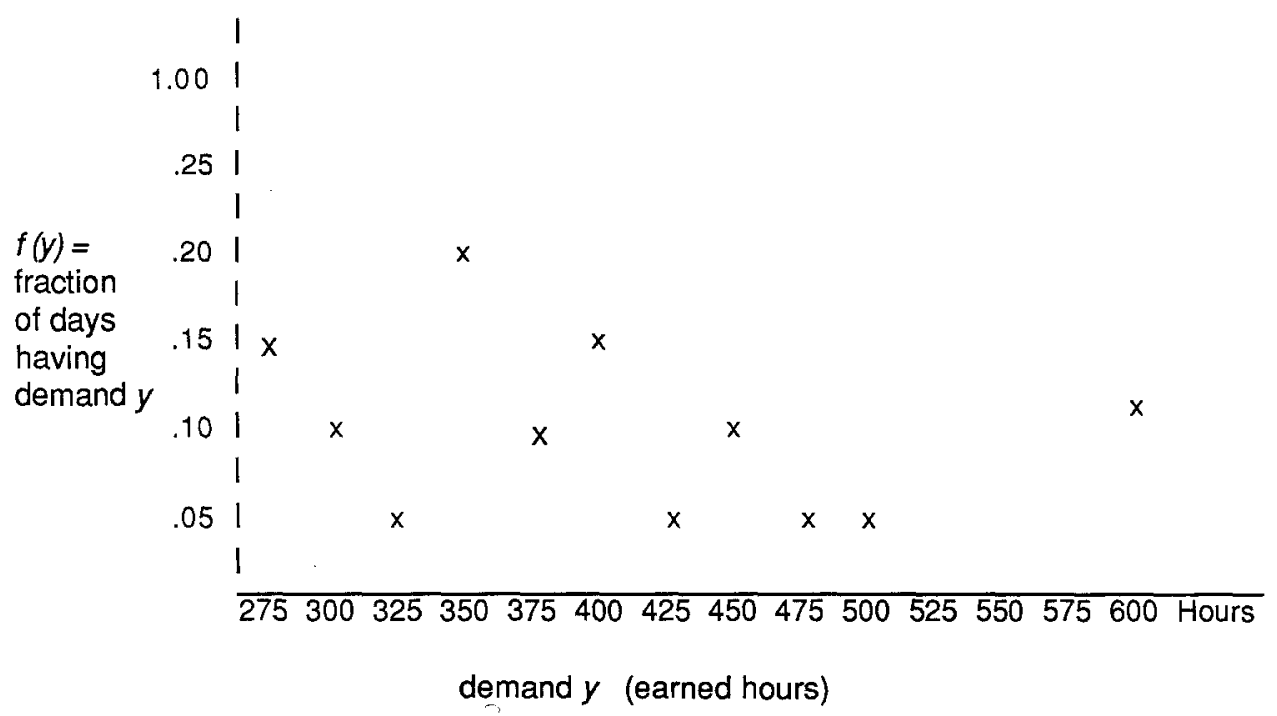

Figure 1. Frequency distribution of demand.

(normally, an 8-hour shift). Since different workers have different capabilities, the work force is characterized by a distribution. For a healthy work force between the ages of 18 and 65 , this distribution is usually described by a bell-shaped curve, such as that shown in Figure 2.

This shape is well represented by the Normal curve

$$
g(t \mid a, \sigma)=\frac{1}{\sqrt{2 \pi} \sigma} e-\frac{(t-a)^{2}}{2 \sigma^{2}}
$$

where $a=$ average capability, $\sigma=$ standard deviation of capability. $a$, the average capability of the work force, is in the range of 1.20 to 1.35 . This is appropriate for excellent labor standards and depends on the personal and fatigue allowances of the specific labor standards used. The value of $\sigma$ is obtained by noting that $95 \%$ of individual workers in good health between the ages of 18 and 65 are capable of performing at or above the capability level of $1.0^{3,6}$ with a value of $a=1.2$ where no personal and fatigue allowances have been added. Then, using the fact that $95 \%$ of a unit normal curve is above -1.645 allows us to compute

$$
\sigma=\frac{1.0-1.2}{-1.645}=.122
$$

Using equation (2) to represent the distribution of capabilities of each member of the work force, it is possible to show that if there are $n$ workers sharing earned hours in a unit, then the total capability they represent is again given by a Normal curve, but with $a$ replaced by $n a$, and $\sigma$ replaced by $\sigma \sqrt{n}$. The Normal curve of equation (2) is of course 


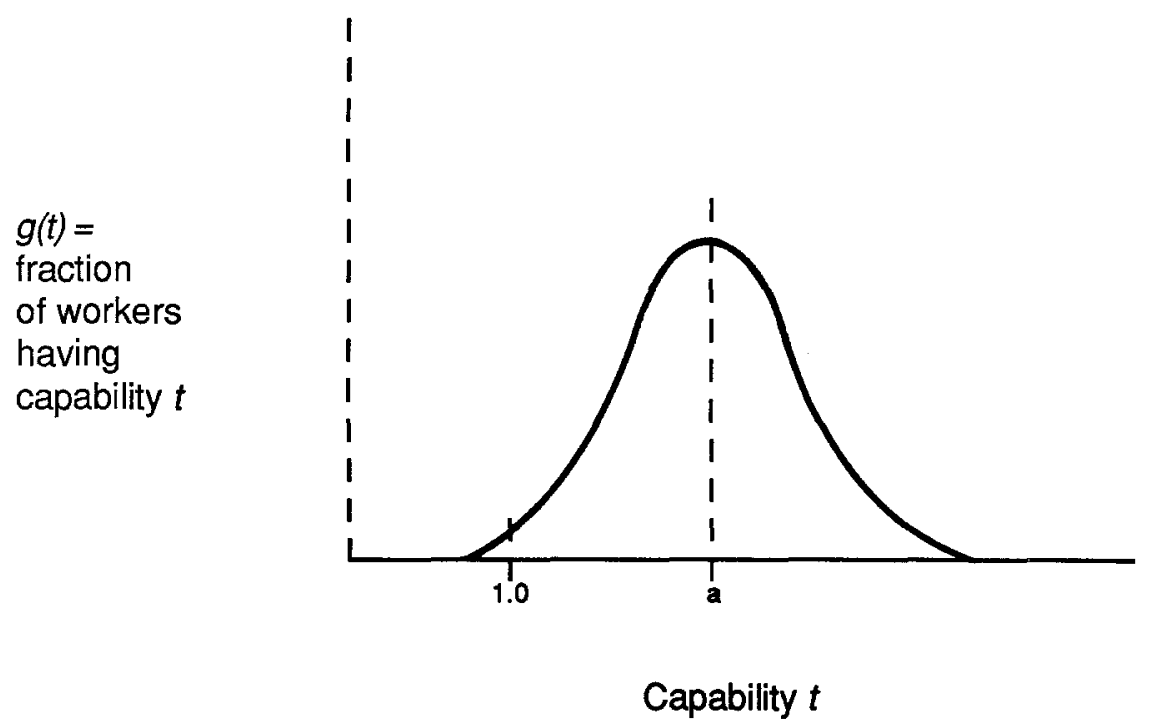

Figure 2. Frequency distribution of work force capability.

an abstraction that should be modified when used to describe an actual single hospital worker's capability. In particular, worker screening and self-selection pressures tend to remove extremely incapable workers or overcapable workers. To reflect these effects, two additional parameters could be used to represent the upper and lower "cutoff" of capabilities. It will be shown, however, that when finding the overall distribution of capabilities for more than a few workers working together, the results are relatively insensitive to such cutoffs. For this reason they are temporarily ignored in the discussion below.

It is often convenient to represent staffing decisions by the allocation of staff hours per shift. If $x=$ allocated staff hours-i.e., the total hours of staff time available for a shift — and each staff member is assigned to an 8-hour shift, then $n=x / 8$.

Thus, the total work (in hours) of a work force assigned to work a total of $x$ staff hours/shift can be shown to be normally distributed, with a mean of $m=a x$ hours/shift and standard deviation of $\sigma \sqrt{8 x}$.

\section{Analysis}

The Appendix shows the details of the analysis that takes the input data

$$
\begin{aligned}
x & =\text { allocated staff hours } \\
c & =\text { average employee cost/hr. (including fringe) } \\
o & =\text { average employee overtime cost } / \mathrm{hr} \text { (including fringe) } \\
f(y) & =\text { frequency distribution for demand } y(E H / \text { shift }) \\
a & =\text { average worker capability } \\
\sigma & =\text { standard deviation of worker capability }
\end{aligned}
$$

and produces output values of expected overtime hours/person, productivity of the work force, probability any overtime is needed on a shift, probability more than $h$ hours of 
overtime on a shift is needed, total costs, overtime costs, and \% productivity of the work force.

\section{EXAMPLES}

\section{Example 1}

Consider an example using the following input data:

Demand $f(y)$ shown in Figure 1 (or, equivalently, in Table 1).

Regular Wages $=c=\$ 16.00 / \mathrm{hr}$. $(\$ 12.00 / \mathrm{hr}$. $+\$ 4.00 / \mathrm{hr}$. fringe benefits $)$.

Overtime Wages $=o=\$ 18.00 / \mathrm{hr}$.

Average capability of the workforce $=a=1.307$. This is a typical value where the personal fatigue and delay allowance of excellent standards is $12 \%$.

Suppose the same number of staff-hours, $x$, is assigned each day. This is equivalent to having a fixed staff 5 days per week. The output* for various values of allocated staff hours $(x)$ is shown in Table 2. The following points are of interest: (1) total cost per day increases as $x$ increases because the upper extreme of the demand distribution is being increasingly performed by the staff on regular time, (2) as $x$ increases the average number

Table 2. Output Measures as a Function of Allocated Hours Every Weekday, for the Demand of Table 1

\begin{tabular}{cccccccc}
\hline $\begin{array}{c}\text { Alloc. } \\
\text { hrs. } \\
(x)\end{array}$ & Staff & $\begin{array}{c}\text { Total } \\
\text { costs }(\$) \\
\text { per day }\end{array}$ & $\begin{array}{c}\text { Overtime } \\
\text { costs }(\$) \\
\text { per day }\end{array}$ & $\begin{array}{c}\text { Average } \\
\text { overtime } \\
\text { hours/ } \\
\text { person/day }\end{array}$ & $\begin{array}{c}\text { Prob. } \\
\text { overtime }\end{array}$ & $\begin{array}{c}\text { P no more } \\
\text { than } 2 \text { hrs. } \\
\text { overtime }\end{array}$ & $\begin{array}{c}\text { Productivity } \\
\text { of } \\
\text { work force }\end{array}$ \\
\hline 336 & 42 & $5,568.79$ & 192.79 & .26 & .246 & .050 & 109.96 \\
344 & 43 & $5,663.79$ & 159.79 & .21 & .199 & .050 & 108.04 \\
352 & 44 & $5,766.58$ & 134.58 & .17 & .154 & .050 & 106.06 \\
360 & 45 & $5,873.38$ & 113.38 & .14 & .136 & .048 & 104.08 \\
368 & 46 & $5,983.65$ & 95.65 & .12 & .108 & .021 & 102.13 \\
376 & 47 & $6,097.01$ & 81.01 & .10 & .095 & .001 & 100.20 \\
384 & 48 & $6,212.91$ & 68.91 & .08 & .068 & 0 & 98.30 \\
392 & 49 & $6,332.49$ & 60.49 & .07 & .051 & 0 & 96.43 \\
400 & 50 & $6,453.24$ & 53.24 & .06 & .050 & 0 & 94.61 \\
408 & 51 & $6,574.03$ & 46.03 & .05 & .050 & 0 & 92.86 \\
416 & 52 & $6,694.82$ & 38.82 & .04 & .050 & 0 & 91.17 \\
424 & 53 & $6,815.63$ & 31.63 & .03 & .050 & 0 & 89.55 \\
432 & 54 & $6,936.43$ & 24.43 & .03 & .050 & 0 & 87.98 \\
440 & 55 & $7,057.22$ & 17.22 & .02 & .050 & 0 & 86.46 \\
448 & 56 & $7,178.06$ & 10.06 & .01 & .049 & 0 & 84.99 \\
456 & 57 & $7,299.72$ & 3.72 & 0 & .034 & 0 & 83.57 \\
464 & 58 & $7,424.54$ & .54 & 0 & .009 & 0 & 82.16 \\
472 & 59 & $7,552.02$ & .02 & 0 & 0 & 0 & 80.77 \\
\hline
\end{tabular}

* The software; "Labor Optimization Program Version 2.6," copyrighted by the University of Michigan, is available for use on the IBM PC. 
Table 3. The Results of Staffing at Different Levels Each Day

\begin{tabular}{|c|c|c|c|c|c|c|}
\hline \multirow[b]{2}{*}{$\begin{array}{c}\text { Week } \\
\text { day }\end{array}$} & \multicolumn{3}{|c|}{ No overtime } & \multicolumn{3}{|c|}{ Maximum of 2 hrs. overtime } \\
\hline & $\begin{array}{c}\text { Staff } \\
\text { (FTE) }\end{array}$ & $\begin{array}{c}\text { Total } \\
\text { cost } \\
\text { per day }\end{array}$ & $\begin{array}{c}\% \\
\text { productivity }\end{array}$ & $\begin{array}{l}\text { Staff } \\
\text { (FTE) }\end{array}$ & $\begin{array}{c}\text { Total } \\
\text { cost } \\
\text { per day }\end{array}$ & $\begin{array}{l}\text { Average \% } \\
\text { productivity }\end{array}$ \\
\hline Monday & 60 & $\$ 7,680.00$ & 101.6 & 48 & $\$ 6,488.55$ & 120.9 \\
\hline Tuesday & 48 & $6,144.00$ & 107.4 & 38 & $\$ 5,313.54$ & 125.4 \\
\hline Wednesday & 40 & $5,120.00$ & 103.5 & 32 & $4,374.95$ & 122.0 \\
\hline Thursday & 40 & $5,120.00$ & 107.4 & 32 & $4,428.33$ & 125.2 \\
\hline Friday & 43 & $5,504.00$ & 96.3 & 34 & $4,591.64$ & 116.1 \\
\hline Totals & & $\$ 29,568.00$ & 103.2 (average) & & $\$ 25,197.01$ & 121.9 (average) \\
\hline
\end{tabular}

of overtime hrs./person/day and the probability of a worker having to work overtime at all (or more than 2 hours) decreases, (3) and the higher the allocated hours, $x$, the lower the average productivity of the work force. One objective of work load staffing will be to guarantee that either (a) there is a small likelihood that a worker will have to work overtime, or (b) there is a small likelihood that a worker will have to work more than, for example, 2 hours overtime.

In particular, in what follows we can define the following constraints:

"No overtime" = minimum staffing such that the probability any given worker has overtime on a shift $\}<.001$.

" 2 hours max overtime" = minimum staffing such that the probability \{any given worker has more than 2 hours of overtime on a shift $\}<.001$.

From Table 2 we can assess the cost and productivity implications to meet such constraints. With "no overtime," 59 FTEs are needed, producing a weekly cost of $\$ 7552.02$ and a productivity of $80.77 \%$. With " 2 hours max. overtime," 48 FTEs are needed, with a productivity of $98.3 \%$ and a total cost of $\$ 6,219.91$. The total cost saving is $17.6 \%$ by use of the change in overtime constraint.

\section{Example 2}

The previous analysis was for an assignment of the same number $(n)$ of full-time staff working every day of the week. Yet the average $E H$ per day of Figure 1 varies from 331 to 488 over the days of the week. This variation in average load is typical in hospitals

Table 4. A Summary of the Alternative Staffing Policies

\begin{tabular}{lcr}
\multicolumn{1}{c}{ Cases } & $\begin{array}{l}\text { Total } \\
\text { costs }\end{array}$ & $\begin{array}{r}\text { Average } \% \\
\text { productivity }\end{array}$ \\
\hline 1. Constant staffing, no overtime & $\$ 37,760$ & 80.8 \\
2. Constant staffing, 2 hrs. max. overtime & 31,065 & 98.3 \\
3. Staffing differently each day, no overtime & 29,568 & 103.2 \\
4. Staffing differently each day, 2 hrs. max. overtime & 25,197 & 121.9 \\
\hline
\end{tabular}


Table 5. Demand (EH) Using "Loose Standards" (10\% Higher Than Figure 1)

\begin{tabular}{cccccc}
\hline Week no. & Monday & Tuesday & Wednesday & Thursday & Friday \\
\hline 1 & 440 & 385 & 330 & 385 & 330 \\
2 & 660 & 495 & 302.5 & 440 & 302.5 \\
3 & 550 & 522.5 & 440 & 302.5 & 357.5 \\
4 & 495 & 412.5 & 385 & 385 & 467.5 \\
\hline
\end{tabular}

because elective surgery is usually done only 5 days/week, which causes a substantial drop in census on weekends and then a gradual increase Monday, Tuesday, and Wednesday. We can thus consider using part-time staff, to augment a base-level full-time staff, and compare the cost and productivity with the "full-time" solution of Table 2. Table 3 shows the results, using different staffing each day, and meeting the two overtime constraints defined above.

Thus, the use of different staffing levels each day results in substantially reduced costs and increases in productivity, over the fixed staffing of Example 1. Table 4 is a summary.

\section{THE EFFECT OF LOOSE STANDARDS}

Loose standards can occur in a number of ways. The most frequent are using existing methods without question, using standards from other hospitals whose methods may be less efficient, granting of personal fatigue and delay allowances (PF\&D) that are not justified, and poor professional work.

As an example, assume that we have compared an existing subset of standards with "excellent" standards and find that the existing standards overstate the time required by $10 \%$. Then Table 5 (obtained by increasing the cell values of Figure 1 by $10 \%$ ) would be the demand as determined by the $10 \%$ "loose" standards.

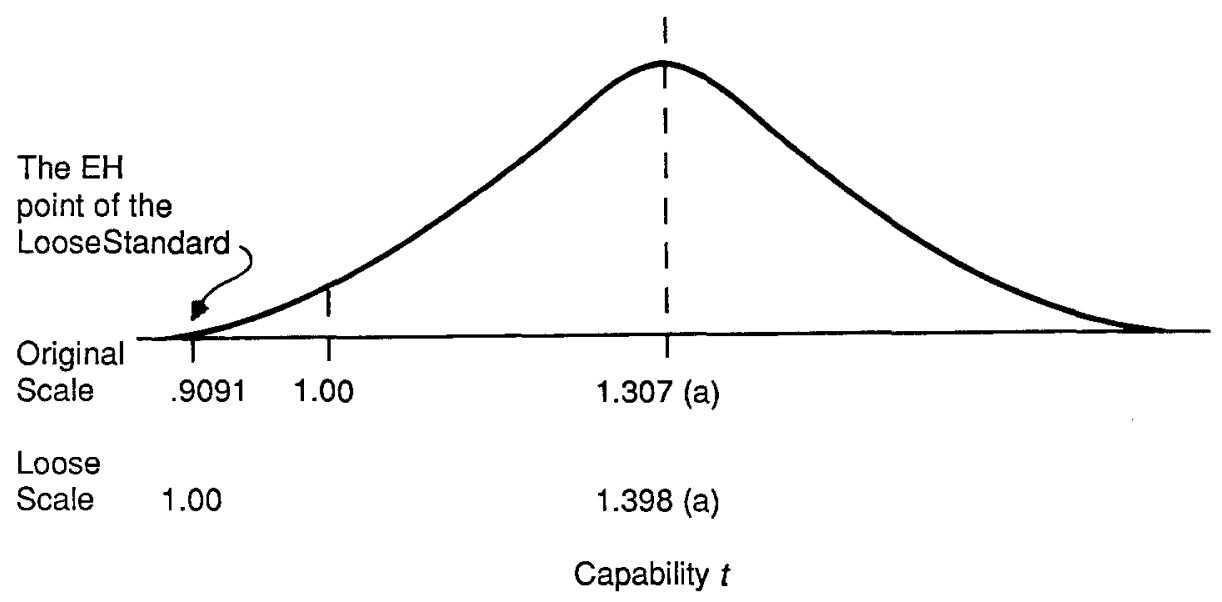

Figure 3. The original capability distribution where average capability $=1.307$ and the standards are set at 1.0., and the $10 \%$ "loose" standard where the standards are set at the .9091 point. 
The original distribution of worker capability had a mean of $a=1.307$. The $10 \%$ loose standard $E H$ point is shown in Figure 3 calculated as being $\frac{100}{1.10}=.9091$. The value of $a$ for the loose standards is $1.398=1.307+(1.00-.9091) . a$ has changed because the point upon which $E H$ is based has been shifted to .9091 . Then the scale has been shifted so that the $E H$ point is 1.0. The following comparison results, using the example of Table 3.

\begin{tabular}{|c|c|c|c|c|}
\hline & \multicolumn{2}{|c|}{$\begin{array}{c}\text { Original } \\
\text { "excellent" standards }\end{array}$} & \multicolumn{2}{|c|}{$10 \%$ loose standards } \\
\hline & Cost & $\begin{array}{l}\text { Average } \% \\
\text { productivity }\end{array}$ & Cost & $\begin{array}{l}\text { Average } \% \\
\text { productivity }\end{array}$ \\
\hline $\begin{array}{l}\text { 1. Constant staffing, } \\
\text { no overtime } \\
\text { 2. Constant staffing, }\end{array}$ & $\$ 37,760$ & 80.8 & $\$ 39,040$ & 85.9 \\
\hline 2 hrs. max. overtime & 31,065 & 98.3 & 31,733 & 105.9 \\
\hline
\end{tabular}

The total costs and productivity of the $10 \%$ loose standards are higher in both cases than the original standards. Note that the expected productivity changes substantially. This will have a major effect on production reporting systems where " $90 \%$ " is considered acceptable.

The reason that the costs are not much higher with the $10 \%$ loose standards is that the looseness of the standard has been compensated for by changing the value of $a$ from 1.307 to 1.398 . If $a$ is not changed because the management engineer is not aware that his/her standards are loose, the following results:

\begin{tabular}{lccccc} 
& \multicolumn{2}{c}{$\begin{array}{c}\text { Original } \\
\text { standards }\end{array}$} & & \multicolumn{2}{c}{$10 \%$ loose standards } \\
\cline { 2 - 3 } & Cost & Productivity $\%$ & & Cost & Productivity $\%$ \\
\hline $\begin{array}{l}\text { 1. Constant staffing, } \\
\text { no overtime }\end{array}$ & $\$ 37,760$ & 80.8 & & $\$ 41,600$ & 80.7 \\
$\begin{array}{l}\text { 2. Constant staffing, } \\
2 \text { hrs. max. overtime }\end{array}$ & 31,065 & 98.3 & & 33,135 & 101.4
\end{tabular}

In this case the cost has increased considerably (approximately 10\%), which is the usual case with poorly established standards.

\section{THE EFFECT OF WORKER SELECTION}

In the previous examples, the entire range of the work force capability distribution was used. However, in many hospital departments the levels of education and training are much greater than the general population. This, in effect, selects out of the working population some portion of the less capable people (a portion of the left-hand tail of the curve of Figure 2).

In order to investigate the sensitivity of our results to this kind of selection process, a truncated capability distribution can be used. Specifically, consider a policy that "selects 
Table 6. The Results of "Selecting Out" the Lowest $20 \%$ of the General Work Force

\begin{tabular}{lccccc}
\hline & \multicolumn{2}{c}{ Full work force } & & \multicolumn{2}{c}{ Lowest 20\% selected out } \\
\cline { 2 - 3 } & $\begin{array}{c}\text { Total } \\
\text { cost }\end{array}$ & $\begin{array}{c}\text { Average } \% \\
\text { productivity }\end{array}$ & & $\begin{array}{c}\text { Total } \\
\text { cost }\end{array}$ & $\begin{array}{c}\text { Average } \% \\
\text { productivity }\end{array}$ \\
\hline $\begin{array}{l}\text { 1. Constant staffing, } \\
\text { no overtime }\end{array}$ & $\$ 37,760$ & 80.8 & & $\$ 36,480$ & 83.6 \\
$\begin{array}{l}\text { 2. Constant staffing, } \\
\text { 2 hrs. max. overtime }\end{array}$ & 31,064 & 98.3 & & 29,809 & 102.5 \\
\hline
\end{tabular}

out" the lower $20 \%$ of the work force. The result is shown in Table 6 . One reason for the small effect (a decrease of about 3.5\% in Total Cost) is the size of the work force. Fifty-eight FTEs (the work force of Table 6) represents a large work group in a hospital. Note that productivity also improves with worker selection.

To explore this effect further, the demand of Table 1 was reduced by a factor of 10 , resulting in the demand of Table 7 , perhaps more typical of a small unit. The results of selecting out $20 \%$ of the smaller work force for the demand of Table 7 are given in Table 8. The reduction in cost is approximately $4.5 \%$ (greater than with the larger work force), and again, productivity increases with worker selection.

Table 7. The Demand of Figure 1 Reduced by a Factor of 10

\begin{tabular}{cccccc}
\hline Week no. & Monday & Tuesday & Wednesday & Thursday & Friday \\
\hline 1 & 40.0 & 35.0 & 30.0 & 35.0 & 30.0 \\
2 & 60.0 & 45.0 & 27.5 & 40.0 & 27.5 \\
3 & 50.0 & 47.5 & 40.0 & 27.5 & 37.5 \\
4 & 45.0 & 37.5 & 35.0 & 35.0 & 42.5 \\
\hline
\end{tabular}

Table 8. Comparison of Selecting Out Low-Capability Workers with Demand Reduced to $1 / 10$ of the Original Demand

\begin{tabular}{llcccc}
\hline & \multicolumn{2}{c}{ No selection } & & \multicolumn{2}{c}{$\begin{array}{c}\text { Select out lowest } \\
\text { 20\% in capability }\end{array}$} \\
\cline { 2 - 3 } \cline { 5 - 6 } & $\begin{array}{c}\text { Total } \\
\text { cost }\end{array}$ & $\begin{array}{c}\text { Average \% } \\
\text { productivity }\end{array}$ & & $\begin{array}{c}\text { Total } \\
\text { cost }\end{array}$ & $\begin{array}{c}\text { Average \% } \\
\text { productivity }\end{array}$ \\
\hline $\begin{array}{l}\text { 1. Constant staff, } \\
\text { no overtime }\end{array}$ & $\$ 4,000$ & 76.8 & & $\$ 3,840$ & 80.0 \\
$\begin{array}{l}\text { 2. Constant staff } \\
\text { 2 hrs. max. overtime }\end{array}$ & $\$ 3,227$ & 95.2 & & $\$ 3,070$ & 100.0 \\
\hline
\end{tabular}

\section{CONCLUSIONS}

The purpose of this paper is to present a model of departmental staffing and, by example, to show the effect of various management policies on the total labor cost, overtime implications, and productivity. This method allows, as an additional benefit, 
the clarification of a department manager's job. He or she assumes responsibility for the staff being available as indicated by the output of the analysis. If the manager properly trains the workers and has them available in the correct numbers, and the work is still not done, then it is not the manager's fault. Rather, the management engineers should then closely examine the standards, the worker capability distributions, and the demand distributions to determine the source of the problem. Thus, responsibilities can be more precisely fixed than with typical labor productivity systems.

The use of the program and the resultant examples reveals the following:

1. Average productivities substantially above $85 \%$ to $90 \%$ are possible with sufficient resources to get all of the work done every day without appreciable overtime.

2. The use of overtime substantially reduces total costs and increases productivity.

3. Changing staff levels over the week (by using part-time employment) results in substantial reductions in budgets and in improvements in worker productivity.

4. An explicit program is available to provide a basis for staff scheduling by giving explicit information about what days people should be asked to work.

5. The direct labor required is directly coupled with the forecasted demand, overtime policies, and policies concerning full- or part-time staff.

6. The effect of "loose" standards on costs and productivity can be demonstrated and can be compensated for by proper knowledge of average work force capability.

7. Budgets can and should be closely connected to staffing policies and expected demand. Otherwise, the work to be done and the staffing supplied may not be compatible with each other. This can result in excess costs or the work's not getting done when it should.

8. The analysis has as a premise that all of the demand will be able to be done every shift using overtime as needed. This is important for medical reasons and for keeping lengths of stay to a minimum.

9. For small work groups, such as typically found in hospitals, worker selection has an important impact on productivity and resultant costs. For larger work units, the effect of selection has less impact.

\section{APPENDIX}

\section{Details of Computation of Output Measures}

This appendix gives the equations that produce costs, overtime hours and probabilities, and productivity, given the following parameters:

$$
\begin{aligned}
x & =\text { allocated staff hours per shift } \\
c & =\text { average employee cost } / \mathrm{hr}, \text {, regular time } \\
o & =\text { average employee cost } / \mathrm{hr}, \text { overtime } \\
f(y) & =\text { frequency distribution for demand }(E H / \mathrm{shift}) . \\
a & =\text { average worker capability } \\
\sigma & =\text { standard deviation of worker capability }
\end{aligned}
$$


$U$ and $L=$ the lower multiplier of the standard deviation of the worker capability distribution.

$g(t \mid m, \sigma)=$ normal distribution of worker capability with mean $m$ and standard deviation $\sigma$, normalized for truncation at $a x+\sigma L \sqrt{8 x}$ and $a x-$ $\sigma U \sqrt{8 x}$.

1. Probability of any overtime in a shift

$$
P_{o}=\int_{a x-L \sigma \sqrt{8 x}}^{a x+U \sigma \sqrt{8 x}} \sum_{y \geqslant t} f(y) g(t \mid a x, \sigma \sqrt{8 x}) d t
$$

2. Probability of more than $h$ total hours of overtime on a shift

$$
P_{h}=\int_{a x-L \sigma \sqrt{8 x}}^{a x+U \sigma \sqrt{8 x}} \sum_{y \geqslant t+h} f(y) g(t \mid a x, \sigma \sqrt{8 x}) d t
$$

3. Expected number of overtime hours on a shift*

$$
c_{o}=\int_{a x-L \sigma \sqrt{8 x}}^{a x+U \sigma \sqrt{8 x}}\left(\sum_{y \geq t} \frac{y-t}{t \mid x} f(y)\right) g(t \mid a x, \sigma \sqrt{8 x}) d t
$$

4. Expected number of overtime hours per sift per FTE $=\frac{8 c_{o}}{x}$

5. Regular time costs $=x \cdot c$

6. Overtime cost $=o \cdot c_{o}$

7. Total cost $=c x+o \cdot c_{o}$

8. Average $\%$ productivity of the work force $=\sum_{\mathrm{y}} f(y) \frac{y}{x+c_{o}} \times 100$

In the software package "Labor Optimization Program, Version 2.6," the integrals are represented by appropriate sum approximations.

\section{REFERENCES}

1. Aberg, U., and Hancock, W.M., Design Criteria of Predetermined Times Systems, International MTM Directorate, Stockholm, Sweden, 1968.

2. Barnes, R.M., Motion and time study. Design and Measurement of Work, Wiley, New York, 1963, 5th ed., p. 344.

3. Karger, D.W., and Hancock, W.M., Advanced Work Measurement, Industrial Press, New York. 1982.

4. Lindner, C., and Hancock, W.M., Computerized work measurement can help hospitals identify cost reduction possibilities. J. Industr. Eng. March: 70-76, 1985.

5. Hancock, W.M., and Chan, T.J., Productivity and staffing of hospital units where the demand for services is variable. IIE Trans. Accepted for publication.

6. Mundel, M.E., Motion and Time Study, Prentice-Hall, Englewood Cliffs, New Jersey, 1950, 4th ed., pp. 304-305.

* Assumes that the work force works at its average capability on overtime. 